\title{
Current Perspective of Beta Thalassemia and Its
}

\section{Treatment Strategies}

Shaukat Ali ${ }^{1, *}$, Shumaila Mumtaz ${ }^{1}$, Hafiz Abdullah Shakir ${ }^{2}$, Hafiz Muhammad Tahir ${ }^{1}$ and Tafail Akbar Mughal ${ }^{1}$

${ }^{1}$ Department of Zoology, Government College University, Lahore, 54000-Lahore, Pakistan

${ }^{2}$ Department of Zoology, University of the Punjab, Lahore, Pakistan

*Corresponding author: Department of Zoology, Government College University, Lahore, 54000-Lahore, Pakistan. Ph: +923054190596. Email: dr.shaukatali@gcu.edu.pk. 
Abstract: Thalassemia is genetic blood disease cause by absence or decrease of one or more of the globin chain synthesis. Beta thalassemia is characterized by one or more mutations in beta globin gene. Absence or reduced amount the of beta globin chains cause ineffective erythropoiesis which leads to anemia. Beta thalassemia has been further divided into three main forms: Thalassemia minor/silent carrier, major and intermedia. More severe form is thalassemia major in which patients depend upon blood transfusion for survival and high level of iron occur as a consequence of consistent blood transfusion. Over loaded iron invokes the synthesis of reactive oxygen species that are toxic in redundancy and triggering the impairment to vascular, endocrine and hepatic system. Thalassemia can be diagnosed and detected through various laboratory tests such as blood smear, prenatal testing (genetic testing of amniotic fluid), DNA analysis (genetic testing) and complete blood count. Treatment of thalassemia intermedia is symptomatic but it can also be managed by splenectomy and folic supplementation. While thalassemia major can be treated by transplantation of bone marrow, regular transfusion of blood and iron chelation treatment, stimulation of fetal hemoglobin production, hematopoietic stem cell transplantation and gene therapy.

Key words: Thalassemia; iron overload; chelation therapy; gene therapy; blood transfusion

\section{Introduction}

Thalassemia is categorized by abnormal production or reduction in rate of formation of normal alpha $(\alpha)$ globin or beta $(\beta)$ globin subunits of hemoglobin $(\mathrm{Hb})$ A. Hemoglobin A comprises of two alpha and two beta globin subunits $(\alpha 2 ; \beta 2)$. Genes responsible for making $\beta$ globin are positioned on chromosome 11 while a globin genes are found on chromosome 16 [1]. Hemoglobin is protein that is present in red blood cells (RBCs) which is accountable for carry the oxygen from alveolus to tissues. There are three types of hemoglobin that are present in 
normal adult such as $\mathrm{HbA}, \mathrm{HbA} 2$ and $\mathrm{HbF}$ that consist of $\alpha 2 ; \beta 2, \alpha 2 ; \delta 2$ and $\alpha 2 ; \gamma 2$ respectively as shown in Figure 1 [2].

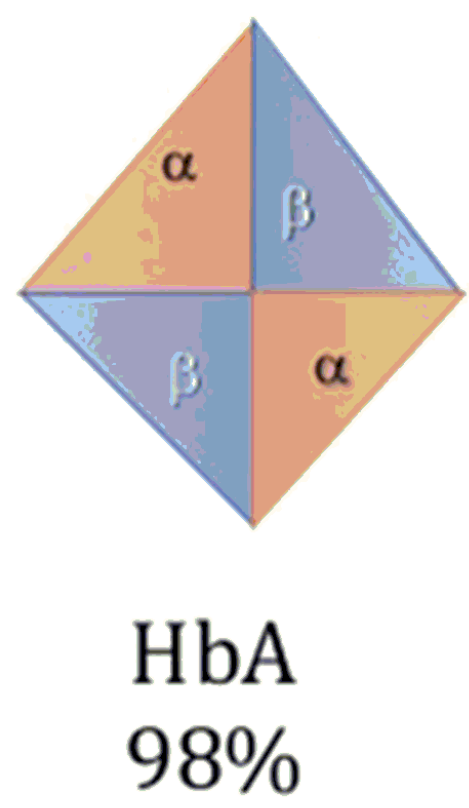

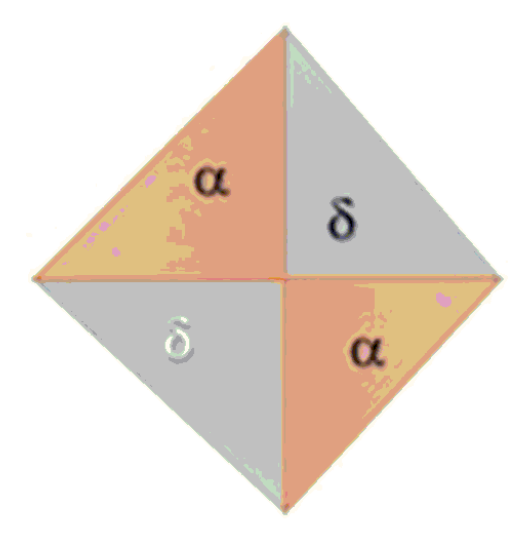

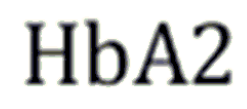

$<3.5 \%$

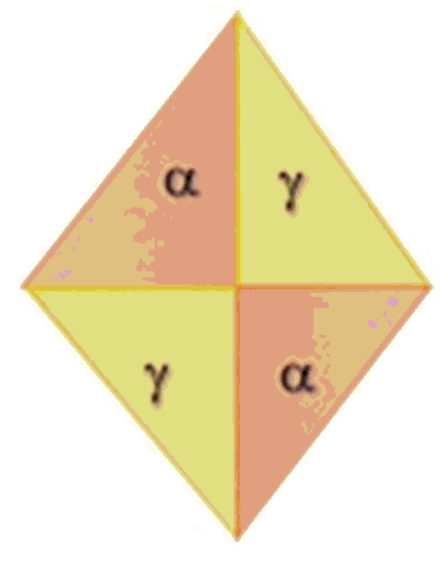

$\mathrm{HbF}$

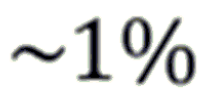

\section{Figure 1: Types of hemoglobin in normal adult.}

Thalassemia is categorized as $\beta, \alpha, \delta \gamma, \delta \beta$ as well as $\gamma \delta \beta$, depending upon which globin chain is affected. While $\alpha$ and $\beta$ thalassemia are two major categories of thalassemia and occurrence depends upon two genes for $\beta$ globin and four genes for alpha thalassemia $[3,4]$. It is produced by more than numerous hundred modifications in the consistent DNA segment. The unpaired globin chains are not stable.They precipitous in cells which lead to immature destruction of precursors of RBCs and shortening of life-span of mature RBCs in blood. Hemoglobin breaks down in iron and heme that catalyze chemical reactions and produce the reactive oxygen species (ROS), which cause the impairment of hepatocytes as well as functions of islets of Langerhans $[1]$.

\section{Beta-thalassemia}


Beta-thalassemia is described by absent or reduction in rate of synthesis of $\beta$ globin chain [5]. It was first time defined by Cooley and Lee in 1925 [6]. The $\beta$ thalassemia is a consequence of substitutions of bases on introns, exons as well as on the promoter regions of $\beta$ globin genes while $\alpha$ thalassemia is a consequence of deletions that remove $\alpha$ gene [7]. It is further categorized according to decreased $(\beta+)$ or absent $(\beta 0)$ globin chain production which might lead to microcytic and hypochromic anemia as well as wide range of syndromic forms [8].

\section{Types of Beta thalassemia}

\section{Beta-thalassemia major}

It is most severe type of thalassemia which is known as Cooley's anemia that occurs either when individuals are homozygous $(\mathrm{B}+/ \mathrm{B} 0, \mathrm{~B} 0 / \mathrm{B} 0)$ or compound heterozygous $(\mathrm{B}+/ \mathrm{B}+)$ for more severe mutations in $\beta$ chain $[9,5]$. It usually induces between six months and two years. In major thalassemia, patients undergo severe anemia (heart failure, fatigue and cachexia) and level of $\mathrm{Hb}$ might be $<7 \mathrm{~g} / \mathrm{dl}$ and $\mathrm{Hb} \mathrm{F}<90 \%$, which result in bone marrow expand to compensate the loss of RBCs which led to bone abnormalities, enlargement of spleen and restriction of growth. The extreme hemolysis leads to pulmonary hypertension, lithiasis and formation of leg ulcer. Furthermore, hypercoagulability is also an impediment of this disorder. Regular management with transfusions of blood or blood products might be overload the iron in various organs which result in diabetes, hypopituitarism complications in liver and endocrine glands such as hypothyroidism, hypopituitarism, hypoparathyroidism, dark metallic pigmentation of the skin, cirrhosis, cardiac arrhythmia, and myopathy which can lead to $71 \%$ death of patients who have thalassemia major [8]. Other complications are HIV infection like prolonged hepatitis B; C, osteoporosis and occlusion in blood as well as patients who possess liver infection have high risk of liver cancers [10]. 


\section{Beta-thalassemia intermedia}

Thalassemia intermedia is a hetrogenous genetic mutation in which individual have little bit ability for production of $\beta$ chain of hemoglobin $(\mathrm{B}+/ \mathrm{B}+, \mathrm{B}+/ \mathrm{B} 0)$. In some situations both $\alpha$ and $\beta$ mutations co-occur [5]. It occurs between 2 and 6 years, have milder anemia and level of hemoglobin varies between 7 and 9-10 g/dL and transfusion of blood is not needed. The sufferer can survive without or only occasionally require blood transfusion as represented in Table I [11].

When bone marrow expand with increasing age, patients may develop many complications such as growth retardation, bone abnormalities infertility and high concentration of iron in several soft tissue owing to elevated the iron immersion in gastro intestinal tract as a result of hemolysis [12].

\section{Beta thalassemia minor}

It is also termed as thalassemia carrier/trait that occurs when one copy of $\beta$ globin gene is normal and one copy is defective $(\mathrm{B} 0 / \mathrm{B}, \mathrm{B}+/ \mathrm{B})$, minor experimental phenotype due to the existence of single normal copy of $\beta$ globin gene $[5,9]$. Thalassemia minor mostly occurs during physiological stress or pregnancy and in childhood. It is an asymptomatic condition; sometimes have a mild anemia due to abnormalities in morphology of erythrocyte [13]. Level of Hb might be $>10 \mathrm{~g} / \mathrm{dl}$ in $\beta$ thalassemia minor or carrier patients. There is a $25 \%$ possibility of homozygous thalassemia at each gestation if both maternities are carriers [14]. 
Table I. Beta thalassemia genotypes clinical features/laboratory features.

\begin{tabular}{|c|c|c|c|c|c|}
\hline$\beta$ Thalassemia & $\begin{array}{l}\text { Globins } \\
\text { Chain }\end{array}$ & $\beta$ Gene & Clinical features & $\begin{array}{l}\text { Laboratory } \\
\text { features }\end{array}$ & References \\
\hline $\begin{array}{l}\text { Thalassemia } \\
\text { Major } \\
\text { (Usually at 4-6 } \\
\text { Months or child } \\
\text { younger than } 2 \text { years) }\end{array}$ & $\begin{array}{l}\alpha 2 \beta 2, \alpha \\
2 \delta 2, \alpha 2 \\
\gamma 2 \\
\alpha 2 \delta 2, \alpha \\
2 \gamma 2\end{array}$ & $\begin{array}{l}\beta+/ \beta+ \\
\beta 0 / \beta 0\end{array}$ & $\begin{array}{l}\text { Anemia } \\
\text { Hepatosplenomegaly } \\
\text { Growth retardation } \\
\text { Require chronic } \\
\text { transfusion; iron } \\
\text { overload }\end{array}$ & $\begin{array}{l}\mathrm{Hb}<7 \mathrm{~g} / \mathrm{dl} \\
\mathrm{Hb} \mathrm{F}<90 \% \\
\mathrm{HbA} 2 \\
\text { normal or } \\
\text { high } \\
\mathrm{HbA} \\
\text { absent }\end{array}$ & {$[8]$} \\
\hline $\begin{array}{l}\text { Thalassemia } \\
\text { Intermediate } \\
\text { (presentation at later } \\
\text { age) }\end{array}$ & $\begin{array}{l}\alpha 2 \beta 2, \alpha \\
2 \delta 2, \alpha 2 \\
\gamma 2\end{array}$ & $\begin{array}{l}\beta+/ \beta 0 \\
\beta+/ \beta+\end{array}$ & $\begin{array}{l}\text { Milder anemia } \\
\text { hepatosplenomegaly }\end{array}$ & $\begin{array}{l}\mathrm{Hb} \\
10 \mathrm{~g} / \mathrm{dl} \\
\mathrm{Hb} \mathrm{F}>10 \% \\
\mathrm{HbA} 24- \\
9 \% \\
\mathrm{HbA} \\
90 \%\end{array}$ & [11] \\
\hline $\begin{array}{l}\text { Thalassemia } \\
\text { minor (Trait) }\end{array}$ & $\begin{array}{l}\alpha 2 \beta 2, \alpha \\
2 \delta 2, \alpha 2 \\
\gamma 2\end{array}$ & $\begin{array}{l}\beta+/ \beta \\
\beta 0 / \beta\end{array}$ & $\begin{array}{l}\text { Asymptomatic } \\
\text { Normal to mild } \\
\text { anemia } \\
\text { No splenomegaly }\end{array}$ & $\begin{array}{l}\mathrm{Hb}>10 \mathrm{~g} / \mathrm{dl} \\
\mathrm{Hb} F 2.5- \\
5 \% \\
\mathrm{HbA} 2 \quad 4- \\
9 \% \\
\mathrm{HbA}\end{array}$ & [14] \\
\hline
\end{tabular}




\section{Hereditary transmission}

Beta thalassemia is a congenital autosomal recessive condition. Children are obligate heterozygotes when parents are affected and bring mutation in a single copy of $\beta$ globin chromosome. At beginning, every offspring of heterozygous parentages has $25 \%$ chance of being unaffected and not carrier, $25 \%$ possibility of being affected and $50 \%$ possibility of being an asymptomatic carrier $[5,15]$.

\section{Pathophysiology}

Figure 2 shows that deficiency ( $(30)$ or declined ( $(+)$ amount of $\beta$ globin chains cause ineffective erythropoiesis which leads to anemia. Erythropoiesis is a result of excess unpaired alpha-globin chains that form unbalanced and insoluble compounds that precipitous in erythroid precursors in the bone marrow and injured the plasma membrane of red blood cells as well as leads to premature destruction of the erythrocytes. This progression mostly occurs in precursors of immature RBCs and in mature RBCs which are called ineffective erythropoiesis/ hemolysis which cause the anemia [16]. Anemia encourages the production of erythropoietin which results in up to 25 to 30 times normal bone marrow expand and the abnormalities occur in bones. The bone marrow compensates the loss of RBCs with accelerated production of RBCs, while it is not sufficient to avoid from severe anemia. Breakdown of erythrocytes cause release of heme which result in increases iron absorption in gastrointestinal tract [17]. High absorption of iron occurs due to inadequate repression of hepcidin (protein that controls duodenal intake of iron). Increased erythropoiesis and consistent blood exchange lead to overload the iron. Overloaded 
iron is an extremely oxidative with lipid peroxidation of membranes and affects numerous organs, especially heart by formation of toxic free radicals [18]. The common inclusions are hemichromes which formed when oxidization of achain subunits take place which interact the proteins spectrin and ankyrin on the membrane. Due to these abnormalities there are increases in cholesterol and phospholipids in membranes and membranes become less stable and more rigid because $\alpha$ chain that are oxidized interact with protein [19]. 

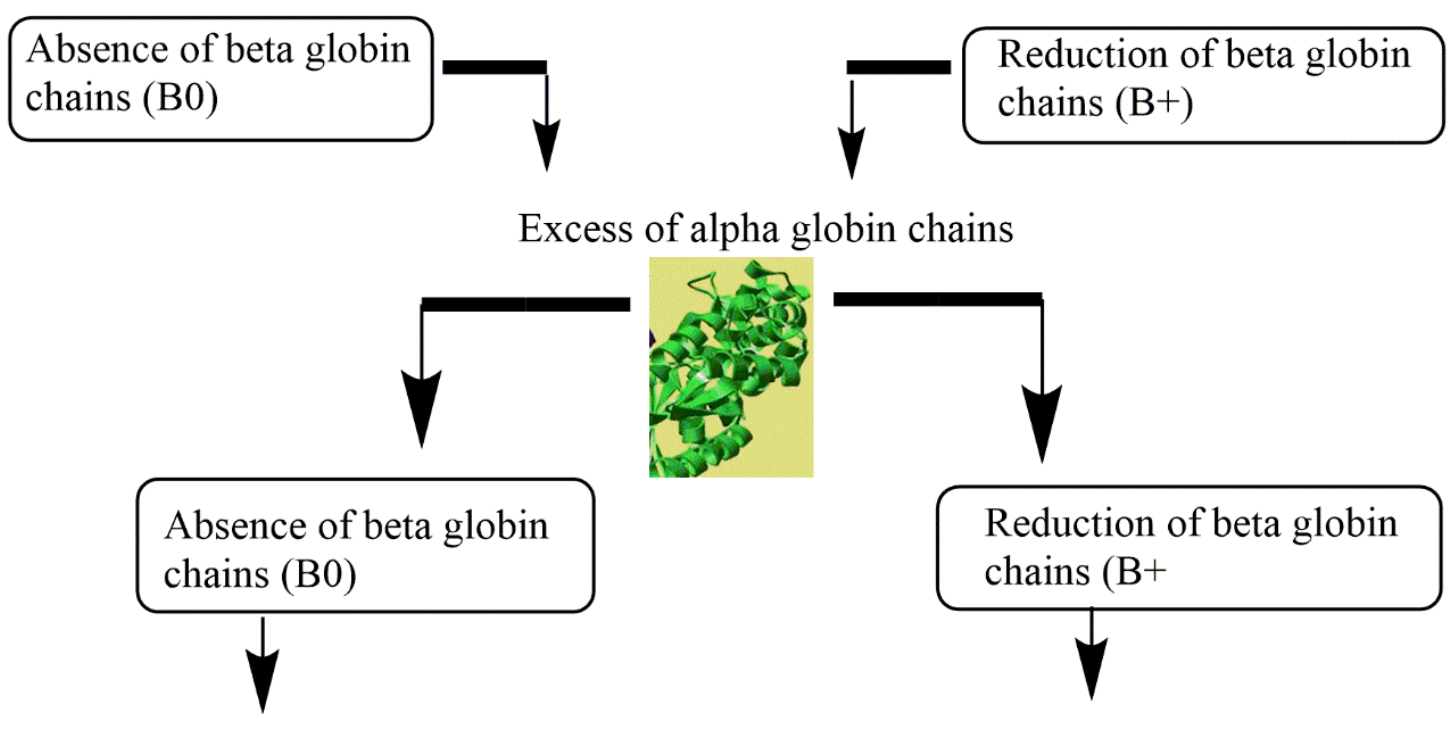

Precipitation in erythroid precurcors within bone marrow<smiles>C1CCCC1</smiles>

Membrane damage to peripheral RBCs

Ineffective erythropoiesis

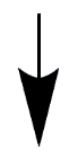

Hemolysis

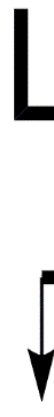
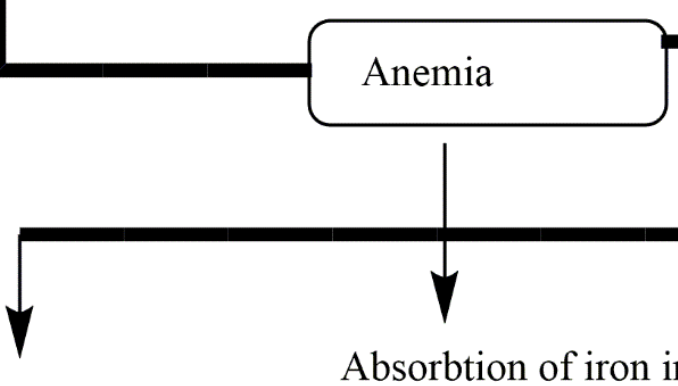

Erythropoietin increased

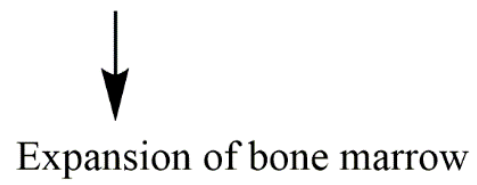

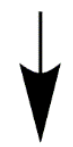

Absorbtion of iron increased

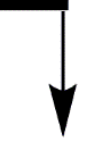

skletal changes/bone deformites

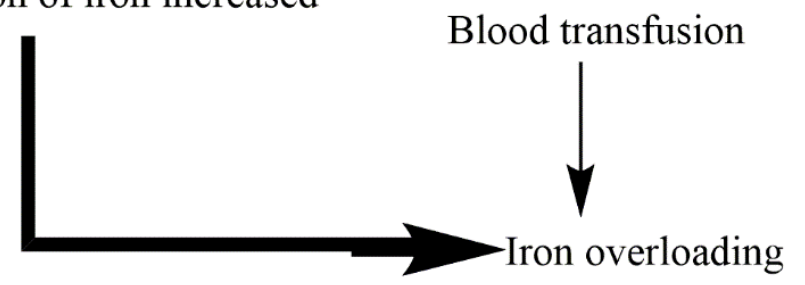

Figure 2: Pathophysiology of Beta Thalassemia 


\section{Medical Indices/Complications}

\section{Iron overload}

Individuals who have more severe forms of $\beta$ thalassemia major or intermediate deposit the iron within the reticuloendothelial system as a consequence of exchange of blood. Overloaded iron appears within various endocrine tissues such as hepatic parenchyma, as well as more slowly in the tissues of heart. Homeostasis of iron in normal humans is accomplished by controlling the concentration of iron [20]. Each day $1 \mathrm{mg}$ of iron is forfeited from the physique, via detaching of the epithelium cells from urinary system, colon, dermis and other endodermal tissues, while 1 $\mathrm{mL}$ of transfused blood possess $1 \mathrm{mg}$ of iron which results in 200 milligram of iron is deposited in tissues. Patients with severe thalassemia who have blood transfusion, a significant capability of deposit the iron due to lacking excretory mechanism of iron from body [21]. During the cellular apoptosis overloaded iron discharges the RBCs which result into ineffective erythropoiesis, that prohibit the management of hepcidin through hepatic system. Hepcidin is a peptide hormone which consists of 25-amino-acid that prohibiting the absorption of dietary iron and deleteriously normalizes flow of iron into serum. It also discharges the accumulated iron from hepatocytes and liberates the iron from kuffer cells [20, 22]. Ferroportin is a multipass transmembrane protein which acts as an iron exporter in spleen and kuffer cells of liver. Primary human hepatocytes of thalassemia patients have suppressed the production of hepcidin in serum as well as reduction of growth differentiation factor 15 (GDF15) prohibited the suppression of hepcidin [17]. Suppression of hepcidin manifestations allows iron release from macrophages and to increase absorption of iron from the intestine. Recently the pathological and normal regulation for synthesis of hepcidin has been studied [23]. Synthesized miniature- hepcidin that has a longer half-life when orally given to mice showed reduction in absorption of iron in mice and also has 
been recommended as prospective useful mediators in severe beta thalassemic patients [24]. After iron release from cells, it is conveyed to the bone marrow and other soft tissue, while up to 20-25 mg iron may circulate as transferrin-bound iron in 24-hour round, while $<1 \%$ of the total body iron remains in circulation at any one time. Iron which is not bind with transferrin or nontransferrin-bound iron (NTBI) is also developing in serum in numerous conformations containing in complex with proteins as well as citrate [25]. Overloaded iron may cause damage in endocrine glands, blood vessels, diabetes, infertility and cirrhosis in liver as shown in figure 3 [26]. Non-transferrin-bound iron enters into tissues through numerous cellular channels that are capable for destruction of cells rather than using the transferrin receptors [27]. Thalassemia patients have the potential to diminish the non-transferrin-bound iron by administrations of chelators [25, 28]. Administration of chelators through intravenously is more effective than subcutaneous administration at reducing NTBI. Various oral chelators such as desferrioxamine removed iron mainly by abolishing the liable plasma iron in serum whereas deferiprone and deferasirox were competent to efficiently admittance as well as diminish the intracellular labile iron segments [29]. Various stratagems have formulated to perceive labile plasma iron (LPI), a portion of the non-transferrin-bound iron pool, activates metabolically by interrelating with components of membrane and affected the plasma membrane through invoke the production of free radicals or reactive oxygen species which stimulate the oxidative stress as well as lead to lipid peroxidation, oxidation of DNA and protein as shown in figure $4[26,30]$. 

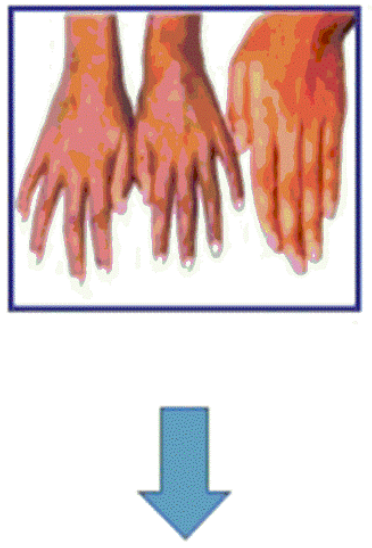

Dark skin

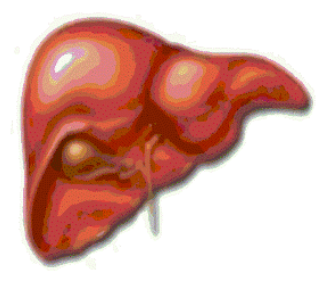

Liver

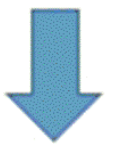

Cirrhosis

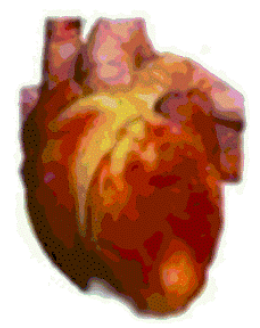

Heart

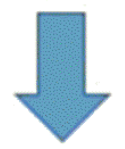

Arrythmia Heart failure

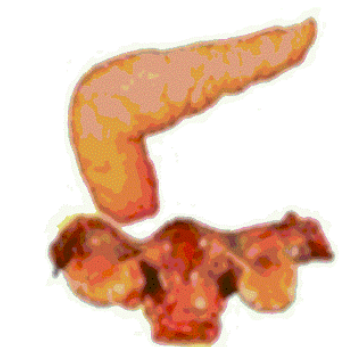

Endocrine organs

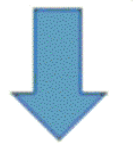

Diabetes Infertility

Pituitary failure Hypothyroidism

\section{Figure 3: Features of iron overload}

\section{Hepatitis}

Patients of thalassemia have a high threat of virus-related contagion. For example, pathological hepatitis due to prolong receiving blood and blood transfusion products. Incidence of hepatitis B for thalassemic patients and donors can greatly reduce due to availability of vaccines but hepatitis $\mathrm{C}$ is a greatly difficult among these patients due to lack of a vaccine [31,32].

\section{Osteoporosis}

Osteoporosis almost occurs in all thalassemia patients which results in multiple fissures such as pain in bone. It also reflects density of minerals in axial bone arises swiftly than fringe bone in old age. Endocrine deficiencies, expansion of bone marrow, potential toxicity of chelators and iron toxicity is also result of osteoporotic in patients of beta thalassemia [33]. Accumulation of iron at a point of $7 \mathrm{mg} / \mathrm{g}$ (dry weight) in hepatocytes might be tolerated, but due to regular transfusion without iron chelation liver fibrosis can occur which result in iron overload and cannot absolutely eradicated from liver which can increase the risk of liver carcinoma [34]. 


\section{Diagnosis}

Thalassemia can be diagnose and detect through various laboratory tests such as blood smear, prenatal testing (genetic testing of amniotic fluid), DNA analysis (genetic testing) complete blood count (CBC), iron studies and hemoglobinopathy [35]. DNA analysis test is used to help detect mutations in genes of $\beta$ and $\alpha$ globin-chain. It can also help to determine carrier status of thalassemia but it not done routinely. Some mutations shows no symptoms while some decline the formation of $\beta g$ lobin chain in $\alpha$ thalassemia as well as some completely prevent the making of beta globin [36].

\section{Hematologic diagnosis}

Thalassemia intermedia is categorized by MCV between 50 and $80 \mathrm{fL}, \mathrm{Hb}$ level from 7 to 10 $\mathrm{g} / \mathrm{dl}$ as well as MCH from 16 and $24 \mathrm{pg}$. Thalassemia carrier/silent is categorized by increased $\mathrm{Hb}$ A2 level with decline $\mathrm{MCH}$ and $\mathrm{MCV}$. Thalassemia major is described by decline MCV > $50<70 \mathrm{fl}, \mathrm{MCH}>12<20 \mathrm{pg}$. and $(>10 \mathrm{~g} / \mathrm{dl}) \mathrm{Hb}$ level $[5,15]$.

\section{Prevention}

Beta-thalassemia might be prevented by identification of carrier, prenatal diagnosis and genetic counseling [37]. Genetic counseling offers evidence for risk of carriers of both parents and risk in offspring. Prenatal diagnosis can be carried out by study of gene take out from cells of fetus about 15-18 weeks of gestation or sampling at 11 week of gestation from chorionic villi. Examination of fetal DNA in serum of mother and investigation of fetal cells in maternal blood might be useful to detect mutations in father [38]. Lymphocytes, trophoblasts and nucleated erythrocytes (NRBCs) are the three types of cell which are utilized as sources of fetus DNA [39]. Burden of thalassemia can be reduced by prevention of birth of homozygotes. Since the last two decades numerous Mediterranean and western countries have succeeded to make substantial 
alteration in the population of homozygote. Some republics such as Turkey, Lebanon, Iran, Canada, Egypt, Malaysia, Pakistan and China also have Thalassemia Control Programs [40].

\section{Treatment}

No treatment is needed to the people who have thalassemia traits. They might be deliberate genetic counseling because mutant gene can pass to their offspring (Mustafa et al, 2016). Individuals with $\beta$ thalassemia intermedia will experience a mild anemia in their life. They may be sentient like normal people however consistent monitoring will require and blood transfusion can be occasionally needed. Iron supplementation is not given, while folic acid supplementation is often recommended [41]. Individuals with thalassemia intermedia will also experience a hypersplenism which may cause growth retardation and worsening anemia and various other mechanical disturbances due to splenomegaly. Treatment of thalassemia intermedia is symptomatic but it can also be managed by splenectomy [42].

\section{Splenectomy}

In thalassemia major and thalassemia intermedia, over activity of the spleen occurs as a consequence of severe hemolysis. Splenomegaly in early age may be prevented after initiation of a regular blood transfusion. However, hypersplenism can develop in children among 5-10 years of age. Splenectomy protects the patients against poor health and growth retardation by decreasing the transfusion requirement, improving the level of $\mathrm{Hb}$ as well as decline the accumulation of iron [43]. Removal of spleen is suggested when a requirement of transfusion is $>200$ to $220 \mathrm{~mL} \mathrm{RBCs} / \mathrm{kg}$ with $70 \%$ hematocrit as well as $250-275 \mathrm{ml} / \mathrm{kg}$ packed RBCs with $60 \%$ hematocrit per year. A meningococcal and pneumococcal vaccine prior to surgical removal of spleen is recommended while after splenetic antimicrobial prophylaxis with penicillin is suggested for reduction of irresistible infections [44]. 


\section{Iron chelation therapy}

In case of regular transmission of blood, each RBC contains $200 \mathrm{mg}$ of iron which results in 0.3$0.6 \mathrm{mg} / \mathrm{kg}$ per day iron accumulated [45]. Iron chelators are categorized into 3 classes (deferasirox (DFX), (deferiprone, (DFP) and (deferoxamine (DFO). Removal of iron is one of the most important managements for those individuals who have blood transfusion [46]. Deferoxamine (DFO) is derivative from treptomyces pilosus with half-life of 8-10 minutes and has a molecular weight of 657. It enters into parenchymal cells of liver where it chelates the iron as the iron chelator feroxamine in plasma and bile. Duration of dose differ from patient to patient and depend upon how much iron is overloaded after transfusion [10]. The initial use of 1 week regularly in transfusion dependent patients of thalassemia, the recommended dose of DFO is 30$40 \mathrm{mg} / \mathrm{kg}$ daily each week and $40-50 \mathrm{mg} / \mathrm{kg}$ and consequently to $60 \mathrm{mg} / \mathrm{kg}$ in teenagers and grownups respectively. Chelation therapy inaugurates, after 20-25 RBCs units are transferred between 2 and 4 years of age [47]. In 1980s DFP which is artificial compound initially wellknown in the New York. Half-life of Defriprone is 1.5-4 hours in plasma and it is absorbed by the Gastro intestinal tract. Dose is recommended daily $75 \mathrm{mg} / \mathrm{kg}$ daily, administration verbally in 3 allocated dosages with mealtimes and this dose might be augmented $100 \mathrm{mg} / \mathrm{kg}$ per day [48]. Defriprone infiltrates cell membranes more swiftly than deferoxamine and it is capable for chelating intracellular iron (Figure 4). It has efficacy for improving function of cardiac by eradicating iron from cardiac as well as preventing cardiac diseases induced by overloaded iron [49]. Regular observation of complete blood count on a weekly basis is required as $1 \%$ of the patients treated with DFP in case of prospective threat of agranulocytosis. Deferasirox DFX (Exjade), hugely bioaccumulative chelator that is immersed in the gut and accepted in 2005 for use in transfusional overloaded individuals [50]. Half-life of deferasirox is 12-18 hours and 
recommended orally once a day. Prescribed dosage is $20-30 \mathrm{mg} / \mathrm{kg}$ daily but some individuals may get assistance through increasing the dosage up to $40 \mathrm{mg} / \mathrm{kg}$ daily it is effective both in grownups as well as offspring [51]. 


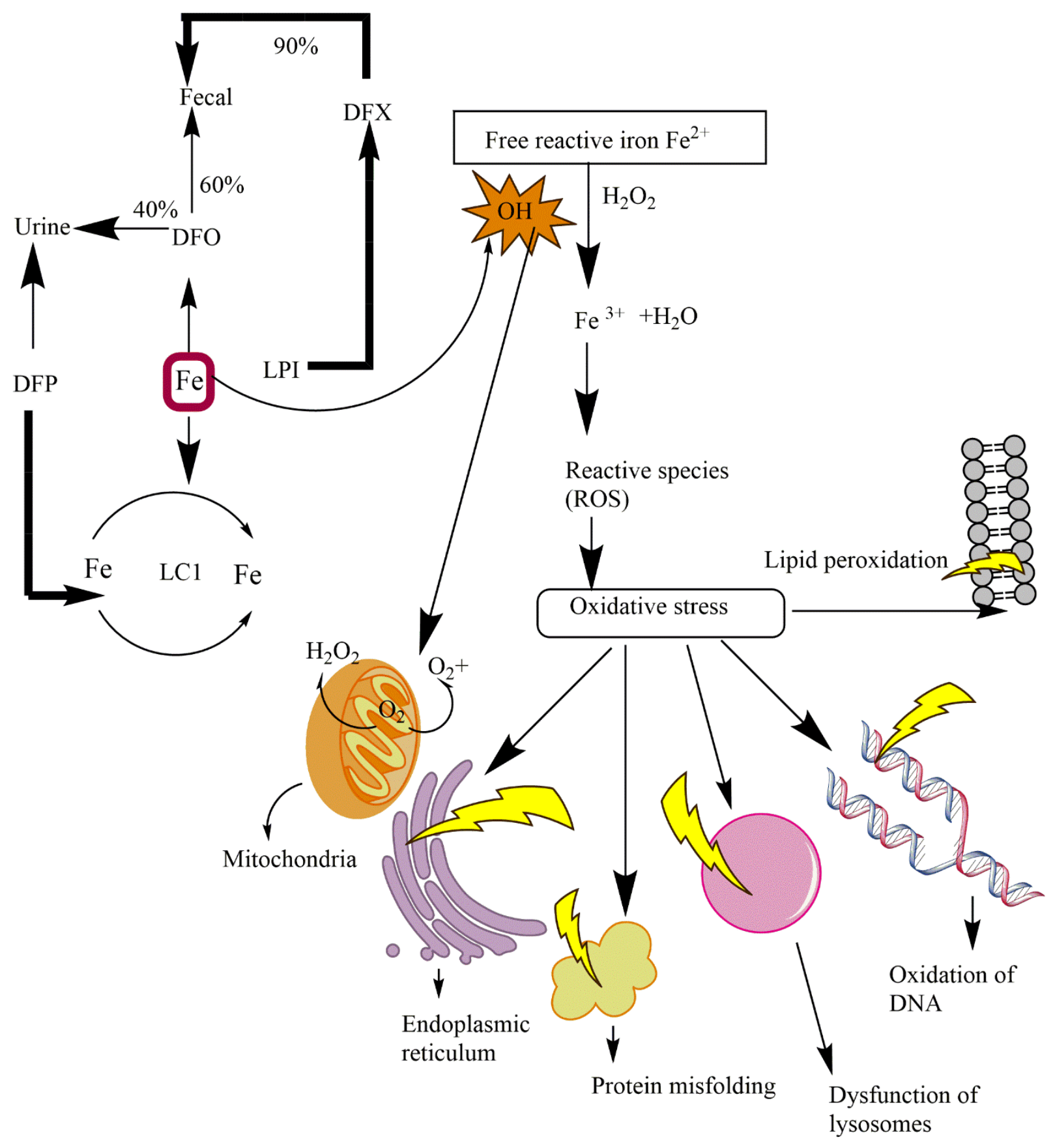

Figure 4: Amelioration of free iron species (Labile plasma iron (LCI) and Labile plasma iron LPI) by iron chelators. Labile plasma iron penetrates via plasma membrane which results in deposition of LCI. Labile plasma iron and labile cell iron produce (ROS) such as free radicals $(\mathrm{OH})$ which oxidize DNA, protein and lipids. Deferiprone (DFP) chelates labile plasma iron and LCI alone or in combination with DFO. Deferasirox (DFX) mostly chelates labile plasma iron. 


\section{Transplantation of bone marrow}

Relocation of bone marrow is still remains the main conclusive treatment, reachable for patients of thalassemia [52]. Main efficacious transplantation of bone marrow was completed in 1980s. The results in young patients are $3 \%$ mortality rate and $87 \%$ thalassemia free survival. But BMT has few disadvantages such as human leukocyte Antigen matched compatible donor is required for this remedial process [53]. The best results with very young individuals are: rejection rate is $23 \%$, mortality rate is $7 \%$ and thalassemia frees survival rate is $70 \%$. Treatment for thalassemia through bone marrow transplantation is still not available for all Indian patients [54].

In low socio-economic countries, the current management available for majority of $\beta$-thalassemia major patient is effective chelating therapy and management of complications of overloaded iron as well as consistent transfusion of packed red cells [55].

\section{Blood transfusion}

The transfusion therapy in $\beta$-thalassemia major is to maintain level of hemoglobin in plasma and to correct anemia which is result of endogenous erythropoiesis [56]. Blood transfusion therapy should be started in case of severe anemia after confirmation the diagnosis of thalassemia. Though, individuals, who have $\mathrm{Hb}>7 \mathrm{~g} / \mathrm{dl}$, various aspects like growth retardation, increasing splenomegaly, facial changes as well as expansion of bone, should be measured. Regular blood transmission would not be late till after the second - third year, because multiple red cell antibodies might be developed and suitable blood donors are difficult to find. Numerous transfusion treatments have been projected over the years; however the utmost extensively conventional goal at pre-transfusion hemoglobin near to 9 to $10 \mathrm{~g} / \mathrm{dl}$ as well as a posttransfusionl level of hemoglobin should be 13 to $14 \mathrm{~g} / \mathrm{dl}$. This inhibits impairment of organs, retardation of growth as well as malformations of bones which might be leads to normal quality 
and activity of life [57] Frequency of blood transfusion depends on numerous causes such as level of hematocrit and $\mathrm{Hb}$ as well as weight of the patient [47]. Blood transfusion therapy should not transfer RBCs more than 15 to $20 \mathrm{ml} / \mathrm{kg}$ daily to evade a profligate rise in volume of blood. Efficiency of transfusion therapy should be examined via pre and post transfusion level of hemoglobin as well as hematocrit because these quantities can enable to monitor iron intake and requirement of RBCs [5].

\section{Gene therapy}

In gene therapy stem cells of patients are utilized for permanent cure of $\beta$ thalassemia major. First a hematopoietic stem and progenitor cells (HSPCs) of patients are harvest from either peripheral blood, bone marrow or umbilical cord blood. After that the tissues/cells are susceptible to a treatment that introduces designed modifications into the genome. The normal $\beta$ or $\gamma$ gene is transferred into the host cell's genome via a lentiviral vector. Transfer of globin gene into progenitor hematopoietic cells is also being deliberate in human [58]. The cells that contain desired genes are again inserted into patients where they multiply and proliferate in the bone marrow. Induced pluripotent stem cells (iPSCs) might be used to avoid the need for highmodification proficiencies in future gene therapies (Figure 5). In this method somatic cells which consist of fibroblasts first isolated from patient and then remodeled into a pluripotent form through manifestations of numerous aspects such as Sox2, Klf4, Oct3/4 and C-Myc [59]. Then induced pluripotent stem cells are susceptible to accomplish the anticipated alteration in genes. An appropriately reformed clone is then prolonged in vitro. After sufficient expansion, induced pluripotent stem cells are then distinguished into hematopoietic stem and progenitor cells. These HSPCs cells are then transferred back into the individual. While this strategy would overcome but this therapy will control many of the extents in directly harvestation of HSPCs from patient 
but HSPCs derived from iPSC is not yet feasible for HSCT because these cells have limitation for multiply in bone marrow.

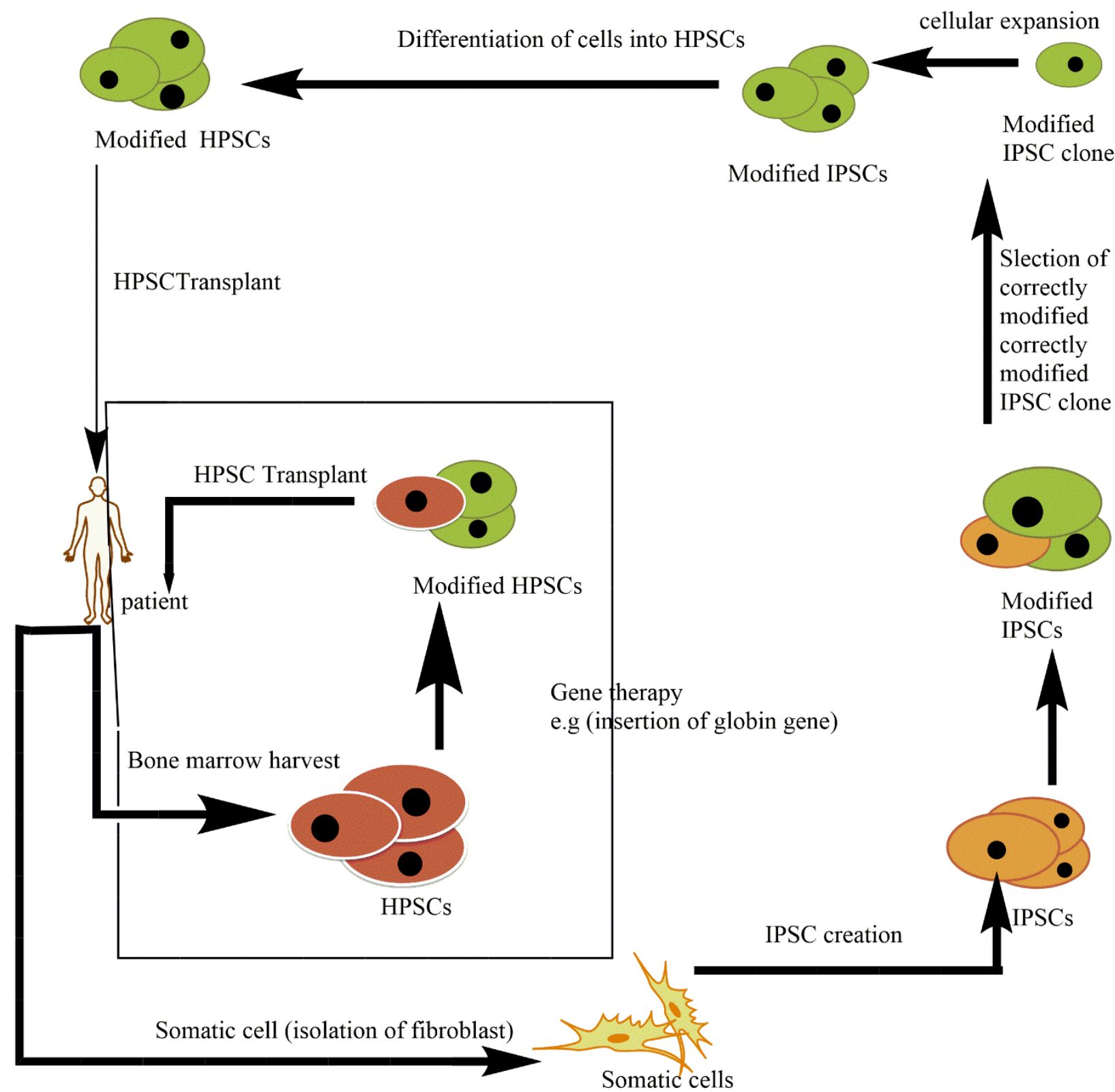

Figure 5: Gene therapy process. Induced pluripotent stem cells (iPSCs), Hematopoietic stem and progenitor cells (HSPCs).

\section{Transplantation of hematopoietic stem Cell}

Thalassemia major might be treated by transplantation of stem cell [60]. This scheme is used in the management of various ailments such as thalassemia. In this therapy, stem cells from the 
bone marrow of healthy persons are sequestered and transmitted to patients of thalassemia. Nearly 80 percent of transplant recipients were successful by this treatment [61]. Graft vs host disease (GVHD) is the most significant and hazardous problem in transplantation of bone marrow which might be leads to death of transfer recipients [62].

\section{Induction of fetal hemoglobin production}

Individuals with long term manifestation of thalassemia, induction fetal hemoglobin enhance the lifetime of RBCs. There are various drugs which are used for stimulation of production of fetal hemoglobin such as hydroxyl urea. Hydroxyurea might be used for cure of both thalassemia and sickle cell disease. Hydroxyurea enhances the production of gamma-globin and also improves hematological and quantifiable signs in patients of thalassemia intermedia [9, 63]. Hydroxyurea acts as a cytotoxic compound for synthesis phase of the cell cycle and also a ribonucleotide reductase inhibitor [64]. It regulates and increase expressions of fetal hemoglobin gene GATA-2 related to apoptosis and cell cycle as well as suppress the countenance of GATA1 gene. It can also induce proliferation of progenitor cells and enhance the amount of erythropoietin [65].

\section{Conclusions}

Beta-thalassemia is induced by modifications in the $\beta$-globin gene which result in completely absent or reduction in rate of synthesis of normal $\beta$ globin chain. The absence of $\beta$ globin chain and excessiveness of the unmatched $\alpha$-globin chains cause oxidative strain and premature destruction of RBCs which result in severe anemia. Blood transfusion therapy recovers the anemia but aggravates the iron overload. It can be prevented by premarital screening, prenatal diagnosis, genetic counseling and carrier detection. Gene therapy and transplantation of bone marrow is still remains the only absolute therapy accessible for thalassemia patients. 


\section{Author contributions}

SA, SM, HAS, HMT and TAM reviewed the literature and wrote the manuscript.

\section{Disclosure}

The authors have no competing interests. 


\section{References}

1. Adly, A. A. M.; El-Sherif, N. H.; Ismail, E. A. R.; El-Zaher, Y. A.; Farouk, A.; ElRefaey, A. M.; Wahba, M. S. Vascular dysfunction in patients with young $\beta$-thalassemia: relation to cardiovascular complications and subclinical atherosclerosis. Clin. Appl. Throm/Hemost. 2015, 21, 733-744.

2. Thein, S. L. Molecular basis of $\beta$ thalassemia and potential therapeutic targets. Blood Cells Mol. Dis. 2018, 70, 54-65.

3. Sirachainan, N.; Chuansumrit, A.; Kadegasem, P.; Sasanakul, W.; Wongwerawattanakoon, P.; Mahaklan, L. Normal hemostatic parameters in children and young adults with $\alpha$-thalassemia diseases. Throm. Res. 2016, 146, 35-42.

4. Gibbs, G.; Burdick, C.O. Separating thalassemia trait and iron deficiency by even simpler inspection. Am. J. Clin. Patholol. 2009, 132, 643-644.

5. Galanello, R.; Origa, R. Beta-thalassemia. Orphanet J. Rare Dis. 2010, 5(1), 11.

6. Franco, S. S.; De Falco, L.; Ghaffari, S.; Brugnara, C.; Sinclair, D. A.; Iolascon, A.; Rimmelé, P. Resveratrol accelerates erythroid maturation by activation of FoxO3 and ameliorates anemia in beta-thalassemic mice. Haematologica 2014, 99, 267-275.

7. Stauder, R.; Valent, P.; Theurl, I. Anemia at older age: etiologies, clinical implications, and management. Blood 2018, 5, 505-514.

8. Lei, M.; Sun, L.; Luo, X. S.; Yang, X.; Yu, F.; Chen, X.; Wang, Z. (Distinguishing iron deficiency anemia from thalassemia by the red blood cell lifespan with a simple CO breath test: A pilot study. J. Breath Res. 2019, 2, 44. 
9. Tari, K.; Ardalan, P.; Abbaszadehdibavar, M.; Atashi, A.; Jalili, A.; Gheidishahran, M. Thalassemia an update: molecular basis, clinical features and treatment. Int. J. Biomed. Public Health 2018, 1, 48-58.

10. Borgna-Pignatti, C. A. T. E. R. I. N. A.; Rugolotto, S. I. M. O. N. E.; De Stefano, P.; Zhao, H. U. A. Q. I. N. G.; Cappellini, M. D.; Del Vecchio, G. C.; Piga, A. Survival and complications in patients with thalassemia major treated with transfusion and deferoxamine. Haematologica 2004, 89, 1187-1193.

11. Birgens, H.; Ljung, R. The thalassaemia syndromes. Scand. J. Clin. Lab. Invest. 2007, 67, 11-26.

12. Taher, A. T.; Musallam, K. M.; Cappellini, M. D.; Weatherall, D. J. Optimal management of $\beta$ thalassaemia intermedia. Brit. J. Haematol. 2011, 152, 512-523.

13. Urbinati, F.; Madigan, C.; Malik, P. Pathophysiology and therapy for haemoglobinopathies; part II: Thalassaemias. Exp. Rev. Mol. Med. 2006, 8, 1-26.

14. Moi, P.; Faà, V.; Marini, M. G.; Asunis, I.; Ibba, G.; Cao, A.; Rosatelli, M. C. A novel silent $\beta$-thalassemia mutation in the distal CACCC box affects the binding and responsiveness to EKLF. Brit. J. Haematol. 2004, 126, 881-884.

15. Canatan, D.; Koç, N. The effect of transfusion on pulmonary function tests in patients with thalassemia. Turk J Haematol. 2004, 3, 137-139.

16. Shariati, L.; Modaress, M.; Khanahmad, H.; Hejazi, Z.; Tabatabaiefar, M. A.; Salehi, M.; Modarressi, M. H. Comparison of different methods for erythroid differentiation in the K562 cell line. Biotechnol. Lett. 2016, 38, 1243-1250.

17. Sangkhae, V.; Nemeth, E. Regulation of the iron homeostatic hormone hepcidin. Adv. Nut. 2017, 8, 126-136. 
18. Hoban, M.D.; Cost, G.J.; Mendel, M.C.; Romero, Z., Kaufman, M.L.; Joglekar, A.V.; Ho, M.; Lumaquin, D.; Gray, D.; Lill, G.R.; Cooper, A.R. Correction of the sickle cell disease mutation in human hematopoietic stem/progenitor cells. Blood 2015, 125, 25972604.

19. Chakrabarti, A.; Bhattacharya, D.; Deb, S.; \& Chakraborty, M. Differential thermal stability and oxidative vulnerability of the hemoglobin variants, $\mathrm{HbA} 2$ and $\mathrm{HbE}$. PloS one, 2013, 8, 818-820.

20. Ganz, T.; Nemeth, E. Hepcidin and disorders of iron metabolism. Ann. Rev. Med. 2011, $62,347-360$.

21. Camaschella, C.; Nai, A. Ineffective erythropoiesis and regulation of iron status in iron loading anaemias. Brit. J. Haematol. 2016, 172, 512-523.

22. Kim, A.; Nemeth, E. New insights into iron regulation and erythropoiesis. Curr. Opin. Hematol. 2015, 3, 199.

23. Finianos, A.; Matar, C.; Taher, A. Hepatocellular carcinoma in $\beta$-thalassemia patients: Review of the literature with molecular insight into liver carcinogenesis. Int. J. Mol. Sci. 2018, 19, 4070 .

24. Preza, G. C.; Ruchala, P.; Pinon, R.; Ramos, E.; Qiao, B.; Peralta, M. A.; Nemeth, E. Minihepcidins are rationally designed small peptides that mimic hepcidin activity in mice and may be useful for the treatment of iron overload. J. Clin. Invest. 2011, 121, 48804888

25. Evans, R. W.; Rafique, R.; Zarea, A.; Rapisarda, C.; Cammack, R.; Evans, P. J.; Hider, R. C. Nature of non-transferrin-bound iron: studies on iron citrate complexes and thalassemic sera. J. Biol. Inorg. Chem. 2008, 13, 57-74. 
26. Hershko, C. Pathogenesis and management of iron toxicity in thalassemia. Ann. N. Y, Acad. Sci. 2010, 1202, 1-9.

27. Wang, C. Y.; Jenkitkasemwong, S.; Duarte, S.; Sparkman, B. K.; Shawki, A.; Mackenzie, B.; Knutson, M. D. ZIP8 is an iron and zinc transporter whose cell-surface expression is up-regulated by cellular iron loading. J. Biol. Chem. 2012, 287, 34032-34043.

28. Fernandes, J. L.; Loggetto, S. R.; Veríssimo, M. P.; Fertrin, K. Y.; Baldanzi, G. R.; Fioravante, L. A.; Coelho, O. R. A randomized trial of amlodipine in addition to standard chelation therapy in patients with thalassemia major. Blood 2016, 128, 1555-1561.

29. Glickstein, H.; El, R. B.; Link, G.; Breuer, W.; Konijn, A. M.; Hershko, C.; Cabantchik, Z. I. Action of chelators in iron-loaded cardiac cells: accessibility to intracellular labile iron and functional consequences. Blood 2006, 108, 3195-3203.

30. Brissot, P.; Ropert, M.; Le Lan, C.; Loréal, O. Non-transferrin bound iron: a key role in iron overload and iron toxicity. Biochim. Biophys. Acta. (BBA)-Gen. Subj. 2012, 1820, 403-410.

31. Soliman, A.; Yassin, M.; Al Yafei, F.; Al-Naimi, L.; Almarri, N.; Sabt, A.; De Sanctis, V. Longitudinal study on liver functions in patients with thalassemia major before and after deferasirox (DFX) therapy. Mediterr. J. Hematol. Infect. Dis. 2014, 6, 322-330

32. Mousa, S.M.O.; Afifi, M.F.; Saedii, A.A.; El-Setohy, A.A. Ischemia modified albumin in children with transfusion-dependent $\beta$-thalassemia: a new marker for an old problem. Egypt. Haematol. 2016, (2), 45.

33. Terpos, E.; Voskaridou, E. Treatment options for thalassemia patients with osteoporosis. Ann. N. Y. Acad. Sci. 2010, 1202, 237-243 
34. Mancuso, A. Hepatocellular carcinoma in thalassemia: A critical review. World J. Hepatol. 2010, 2, 171.

35. Alqahtani, R. S.; Bedaiwi, A. A.; Alburkani, A. M.; AlFahed, M. M.; Alhoraibi, R. A.; Tarawah, A. M. Knowledge and response of the community to premarital screening program (Sickle Cell AnemialThalassemia). AlMadinah Saudi Arabia J. Appl. Hematol. 2018, 9, 59.

36. Sagar, C. S.; Kumar, R.; Sharma, D. C.; Kishor, P. Alpha hemoglobin stabilizing protein: Its causal relationship with the severity of beta thalassemia. Blood Cells Mol. Dis. 2015, $55,104-107$.

37. Origa, R.; Comitini, F. Pregnancy in thalassemia. Mediterr. J. Hematol. Infect. Dis. 2019, $11,120$.

38. Mavrou, A.; Kouvidi, E.; Antsaklis, A.; Souka, A.; Kitsiou Tzeli, S.; Kolialexi, A. Identification of nucleated red blood cells in maternal circulation: a second step in screening for fetal aneuploidies and pregnancy complications. Prenatal Diagnosis: Published in Affiliation With the International Society for Prenatal Diagnosis 2007, 27, $150-153$.

39. Colah, R.; Gorakshakar, A.; Nadkarni, A. Global burden, distribution and prevention of $\beta$-thalassemias and hemoglobin E disorders. Exp. Rev. Hematol. 2010, 3(1), 103-117.

40. Madan, N.; Sharma, S.; Sood, S. K.; Colah, R.; Bhatia, H. M. Frequency of $\beta$-thalassemia trait and other hemoglobinopathies in northern and western India. Ind. J. Hum. Genet. 2010, 16, 16. 
41. Kumar, R.; Sharma, D. C.; Kishor, P. (Hb E/ $\beta$-Thalassemia: The Second Most Common Cause of Transfusion-Dependent Thalassemia in the Gwalior-Chambal Region of Central India. Hemoglobin 2012, 36, 485-490

42. Origa, R. Combination therapies in iron chelation. Thalassemia Reports, 2014, 4(3).

43. Pecorari, L.; Savelli, A.; Guna, C. D.; Fracchia, S.; Borgna-Pignatti, C. The role of splenectomy in thalassemia major. An update. Acta Pediatrica Mediterr. 2008, 24, 57-60.

44. Ikeda, M.; Sekimoto, M.; Takiguchi, S.; Kubota, M.; Ikenaga, M.; Yamamoto, H.; Tatsuta, M. High incidence of thrombosis of the portal venous system after laparoscopic splenectomy: a prospective study with contrast-enhanced CT scan. Ann. Surg. 2005, 241, 208.

45. Sarker, N. R.; Ghosh, A. K.; Saha, S. K.; Shahriar, A. Recent advances in the management of Thalassaemia: A Review Update. J. Shaheed Suhrawardy Med. Coll. 2014, 6, 31-37.

46. Adewoyin, A.S; Oyewale, O.A. Complications of allogeneic blood transfusion: Current approach to diagnosis and management. Int. Blood Res. Rev. 2015, 3, 135-151.

47. Taher, A.T.; Weatherall, D.J.; Cappellini, M.D. Thalassaemia. The Lancet, 2018, 391, $155-167$.

48. Crisponi, G.; Nurchi, V. M.; Lachowicz, J. I. Iron Chelation for Iron Overload in Thalassemia. Essential Metals in Medicine: Therapeutic Use and Toxicity of Metal Ions in the Clinic 2019, 19, 49.

49. Piga, A.; Gaglioti, C.; Fogliacco, E.; Tricta, F. Comparative effects of deferiprone and deferoxamine on survival and cardiac disease in patients with thalassemia major: a retrospective analysis. Haematologica 2003, 88, 489-496. 
50. Cappellini, M. D.; Porter, J.; El-Beshlawy, A.; Li, C. K.; Seymour, J. F.; Elalfy, M.; Lin, K. H. Tailoring iron chelation by iron intake and serum ferritin: the prospective EPIC study of deferasirox in 1744 patients with transfusion-dependent anemias. Haematologica 2010, 95, 557-566.

51. Cappellini, M. D.; Cohen, A.; Piga, A.; Bejaoui, M.; Perrotta, S.; Agaoglu, L.; Capra, M. A phase 3 study of deferasirox (ICL670), a once-daily oral iron chelator, in patients with $\beta$-thalassemia. Blood 2006, 107, 3455-3462.

52. Rivière, I.; Dunbar, C. E.; Sadelain, M. Hematopoietic stem cell engineering at a crossroads. Blood 2012; 119, 1107-1116.

53. Sabloff, M.; Chandy, M.; Wang, Z.; Logan, B. R.; Ghavamzadeh, A.; Li, C. K.; Hale, G. A. HLA-matched sibling bone marrow transplantation for $\beta$-thalassemia major. Blood 2011, 117, 1745-1750.

54. Sharma, D.C.; Singhal, S.; Woike, P.; Tomar, A.S.; Rawat, N.; Arya, A.; Gaur, R. Red Blood Cells Alloimmunization and Transfusion Strategy in Transfusion Dependent BThalassemia Patients. IOSR-JDMS, 2016, 15, 10-14.

55. Ganguly, S.; Bradley, J. P.; Patel, J. S.; Tilzer, L. Role of transfusion in stem cell transplantation: a freedom-from-transfusion (FFT), cost and survival analysis. J. Med. Econo. 2010, 13, 55-62.

56. Cihan, M.K.; Belen, B.; Bolat, F., Bülbül, Ö.G.; Korgal1, E.Ü.; Koçak, Ü.. The Impact of Transfusion and Chelation on Oxidative Stress in Immigrant Syrian Children with $\beta$ Thalassemia. Ind. J. Hematol. Blood Transfus. 2017, 4, 552-558.

57. Kadhim, K.A.; Baldawi, K.H.; Lami, F.H. Prevalence, incidence, trend, and complications of thalassemia in Iraq. Hemoglobin 2017, 41, 164-168. 
58. Breda, L.; Kleinert, D. A.; Casu, C.; Casula, L.; Cartegni, L.; Fibach, E.; Rivella, S. A preclinical approach for gene therapy of $\beta$-thalassemia. Ann. N. Y. Acad. Sci. 2010, 1202, 134-140.

59. Takahashi, K.; Yamanaka, S. Induction of pluripotent stem cells from mouse embryonic and adult fibroblast cultures by defined factors. Cell 2006, 126, 663-676.

60. Angelucci, E.; Matthes-Martin, S.; Baronciani, D.; Bernaudin, F.; Bonanomi, S.; Cappellini, M.D. Hematopoietic stem cell transplantation in thalassemia major and sickle cell disease: indications and management recommendations from an international expert panel. Haematologica 2014, 99, 811-820.

61. Bernardo, M.E.; Piras, E.; Vacca, A.; Giorgiani, G.; Zecca, M.; Bertaina, A. Allogeneic hematopoietic stem cell transplantation in thalassemia major: results of a reduced-toxicity conditioning regimen based on the use of treosulfan. Blood 2012, 120, 473-476.

62. King, A.; Shenoy, SEvidence-based focused review of the status of hematopoietic stem cell transplantation as treatment of sickle cell disease and thalassemia. Blood 2014, 123 3089-3094.

63. Wilber, A.; Hargrove, P.W.; Kim, Y.STherapeutic levels of fetal hemoglobin in erythroid progeny of $\beta$-thalassemic CD34+ cells after lentiviral vector-mediated gene transfer. Blood 2011, 117, 2817-26.

64. Fard, A.D.; Hosseini, S.A.; Shahjahani, M.; Salari, F.; Jaseb, K. Evaluation of novel fetal hemoglobin inducer drugs in treatment of $\beta$-hemoglobinopathy disorders. Int. J. Hematol Oncol. Stem Cell Res. 2013, 7, 47-54. 
65. Tang, D.C.; Zhu, J.; Liu, W.; Chin, K.; Sun, J.; Chen, L. The hydroxyurea-induced small GTP-binding protein SAR modulates $\gamma$-globin gene expression in human erythroid cells. Blood 2005, 106, 3256-3263. 